\title{
O PERFIl da nOVA Classe média e a INFLUÊnCIA do CAPITAL CULTURAL
}

\author{
PROFILE OF THE NEW MIDDLE CLASS AND THE INFLUENCE OF CULTURAL CAPITAL
}

Recebido em 29.05.2014. Aprovado em 03.12.2014 Avaliado pelo sistema double blind review

DOI: http://dx.doi.org/10.12712/rpca.v8i4.452

\author{
Sâmara Borges Macedo \\ samaraborgesmacedo@outlook.com \\ Universidade Federal de Lavras - Lavras - MG - Brasil \\ Aline Pereira Sales \\ alineadmufla@yahoo.com.br \\ Universidade Federal de Lavras - Lavras - MG - Brasil

\section{Daniel Carvalho Rezende} \\ danielderezende@dae.ufla.br \\ Universidade Federal de Lavras - Lavras - MG - Brasil
}

\section{Resumo}

Diante de tantas mudanças no cenário econômico, surge uma Nova Classe denominada como a Nova Classe Média. Por ser tão heterogênea, torna-se importante compreender o perfil dessa nova classe detentora de um grande poder de compra e consequentemente capaz de intensificar a movimentação da economia nacional. Com isso o presente estudo tem como objetivo caracterizar o consumo da Nova Classe Média e identificar a influência que o Capital Cultural exerce na mesma. Para desenvolver o estudo, foram realizadas 25 entrevistas em profundidade que foram transcritas e analisadas. Os resultados permitiram observar como o consumo da Nova Classe Média se dá e como o nível de Capital Cultural a influencia. Essa classe demonstrou características peculiares como medo em relação ao futuro o que implica a necessidade de poupar dinheiro e acreditar que a capacitação será uma forma de diferenciá-los e mantê-los nessa posição social, tornando-se assim uma medida de sustentabilidade.

Palavras-chave: Nova Classe Média. Capital Cultural. Consumo

\begin{abstract}
A New Class named as the New Middle Class emerges in face of so many changes in the economic scenario. It is important to understand the profile of this New Class that is so heterogeneous and holds a strong purchasing power beyond it is capable of enhancing the movement of the national economy. Thus this study aims to characterize the consumption of the New Middle Class and identify the influence that cultural capital plays in it. For developing this study, 25 in-depth interviews were conducted and then they were transcribed and analyzed. Results showed how the consumption of New Middle Class takes place and how it's influenced by the Cultural Capital level. This class showed peculiar characteristics such as fear about the future which implies the need to save money and believe that training is a way to distinguish and keep them on this social position, thus becoming a measure of sustainability.
\end{abstract}

Keywords: New Middle Class. Cultural Capital. Consumption. 


\section{Introdução}

A classe média brasileira assumiu expressiva importância no cenário econômico, isto em função do aumento de 228,3\% dos seus gastos com produtos e serviços entre 2001 e 2011. Assim, neste mesmo período, a classe média ampliou de $25,8 \%$ para $44,3 \%$ a sua participação no consumo nacional, ultrapassando a classe alta, que caiu de $58,5 \%$ para $39,9 \%$ a sua representatividade (BRASIL, 2012).

É inegável a representatividade que essa Classe tem hoje no consumo nacional, afirmando assim seu poder de compra, fazendo com que os consumidores da Nova Classe Média tenham em mãos um grande poder sobre o mercado. As organizações terão de saber lidar com esse novo público e saber quais as aspirações, desejos e motivações da Nova Classe a fim de compreender e atender às exigências desse novo mercado tão peculiar (MEIRELLES, 2011).

Segundo Lamounier (2010) por ser uma classe tão ampla não existe homogeneidade comportamental. Nesse sentido, torna-se importante compreender a influência que o Capital Cultural exerce nos padrões de consumo da Nova Classe Média uma vez que o mesmo é um processo relacionado à educação, podendo ser formal, no ambiente escolar, bem como social, herdado e influenciado pela família, como gostos, preferencias e hábitos, portanto, relacionado também a questão social (BOURDIEU, 1983). Neste contexto, o presente estudo tem como objetivo caracterizar o consumo da Nova Classe Média e identificar a influência que o Capital Cultural exerce na mesma.

Apesar do crescimento dos estudos relacionados a Nova Classe Média, pouco ainda foi estudado sobre a influência que o Capital Cultural possui nos padrões de consumo da mesma, justificando assim a relevância desse estudo.

As próximas seções destinam-se a apresentação do referencial teórico, abordando os conceitos sobre a Nova Classe Média, bem como os conceitos de Capital Cultural. 0 tópico seguinte é dedicado à descrição dos procedimentos metodológicos utilizados na realização dessa pesquisa. Em seguida, os resultados obtidos são apresentados. Por fim, são feitas as considerações finais desse trabalho.

\section{A Nova Classe Média Brasileira}

Desde o século XX os estudiosos voltaram-se para os estudos relacionados a estratificação de classes, porém nenhum critério ainda foi assumido como ideal (ESTANQUE, 2002). As definições se deram de várias formas, no mundo todo. Algumas consideradas multidimensionais e unidimensionais. Alguns consideram vários critérios para se definir uma classe e alguns autores escolhem somente um, tornando-os unidimensional. 0 critério único utilizado mais comumente pelos estudiosos é a renda.

No caso do presente estudo, como o foco é a classe média, será apresentado quais os critérios utilizados para se definir tal classe. Primeiro busca-se entender o que vem a ser classe social. Barros(1986), demonstrou em seu trabalho dificuldade e definir o termo em questão. A mesma dificuldade apresentada há quase 30 anos ainda se faz atual. Uma clássica visão sobre classe social é a defendida por Marx (apud Matoso, 2005), onde Estuda as classes de forma dicotômica, havendo então as classes: burguesa e proletariada, a dominadora e a dominada, os que tem capital e os da força de trabalho. Nessa visão têm-se as classes de acordo com os modos de produção de cada estrato. Classes abordas de maneira dicotômica foi alvo do estudo de Singer (1981), onde a autora aponta a existência de duas Classes no Brasil : a burguesa e a proletariada. Sendo a primeira decomposta duas : empresarial e gerencial. 
O que diferencia a visão de Singer (1981) em relação a defendida por Marx é o fato de acrescentar às duas definições básicas uma outra divisão, a pequena burguesia, comporta por trabalhadores, proprietários de seus meios de produção.

Outras duas definições de classes sociais que contribuíram para as definições encontradas atualmente são as apresentadas por Weber e Bourdieu. Weber (1976), relaciona as classes sociais ao status, apresentando assim uma visão de classes mais voltada aos estudos em marketing e Bourdieu (1979), relaciona classes sociais à distinção por gostos e preferências, envolvendo assim hierarquia social e distinção por consumo.

Para Schiffman e Kanuk (2000) não existe um consenso definitivo de como se deve medir as classes. Em se tratando de classes populares, Prado (2008) corrobora ao afirmar que devido às modificações ocorridas nas classes consideradas populares torna-se difícil um consenso em relação a terminologias. Krakauer (2010) considerou os consumidores da classe média como sendo consumidores emergentes. "O conceito de classe social é um dos mais tradicionais, e, ainda assim, um dos mais controversos no campo das ciências humanas." (SOBRINHO, p 72, 2011).

Inúmeros blogs, sites, revistas e jornais de grande circulação nacional e veiculação internacional publicam reportagens sobre a tão famosa Nova Classe Média brasileira e todos seus desdobramentos. Mas ainda hoje não há uma única definição para essa Nova Classe. Não há um critério único. Um dos sites mais populares na atualidade é o Data Popular, pertencente a Renato Meirelles, que presta consultorias e faz inúmeras pesquisas voltadas para essa Nova Classe, traçando perfis, estudando tendências, comportamentos, etc. No entanto, no que tange ao meio acadêmico ainda se faz presente a não definição de um conceito para a chamada Nova Classe Média. Estudos acadêmicos têm sido realizados de forma mais substancial nos últimos anos, reafirmando assim o potencial em se estudar essa classe que tem se mostrado tão economicamente ativa e influenciando tantas mudanças na sociedade.

A título de esclarecimento, vale destacar que no presente estudo será considerado como a Nova Classe Média a também chamada Nova Classe $C$ ou Classe $C$, visto que tal nomeclatura também é bem difundida entre os diversos autores citados.

Salata (2012, p.2), em seu estudo sobre a Nova Classe Média constatou que o critério mais utilizado para definição de classes surge nos estudos da área econômica e que as discussões ainda giram em torno da "melhor maneira de se tratar a variável renda a fim de se identificar a classe média.

Em um levantamento realizado pela FGV, coordenado por Neri (2010), a Classe C é definida como a classe central, abaixo da A e B e acima da D e E. A fim de quantificar as faixas, foi calculado a renda domiciliar per capita e depois foi expressa em termos equivalentes de renda domiciliar total de todas as fontes. A faixa C central está compreendida entre os $\mathrm{R} \$ 1064$ e os R\$ 4561 a preços da grande São Paulo referente a 2010. Ainda segundo o estudo realizado pela FGV-:

A mesma [classe C] que atingia 37,56\% da população brasileira em 2003, passa a 50,45\% em 2009, ou 94,9 milhões de brasileiros que tem renda acima de 1126 até 4854 reais mensais, a classe dominante no sentido populacional. (FGV, p.31)

Prahalad (2005) estratifica o Brasil em cinco classes sociais, A, B, C, D e E, e considera a Classe Média como a parcela da população com renda familiar entre 4 e 10 salários mínimos. Outros autores como Parente, Limeira e Barki (2008) também utilizam a renda familiar baseada em salários mínimos para definir classes, definindo a Classe média como a população que possui renda familiar entre 5 e 10 salários mínimos. Mas vale ressaltar que são considerados também 
alguns outros fatores, como escolaridade.

O Instituto Brasileiro de Geografia e Estatística (IBGE) também baseia-se no número de salários mínimos para definir as classes sociais. E as divide em 5: A, B, C, D e E (IBGE, 2006) . Esta metodologia não considera a renda per capita, considerando o valor da renda familiar total, assim como os autores supracitados. Um critério que considera a renda per capita, ou renda domiciliar média foi o desenvolvido pelo instituto de pesquisa Data Popular, onde apesar de usar a renda per capita como critério, também classifica as classes sociais como A, B, C, D e E. A comissão da SAE (Secretaria de Assuntos Estratégicos da Presidência da República) definiu como classe média brasileira as pessoas com renda familiar per capita entre cerca de R 291 e $\mathrm{R} \$ 1.019$.

O Critério de Classificação Econômica Brasil (CCEB), desenvolvido pela Associação Brasileira de Empresas de Pesquisa (ABEP), utiliza outros critérios para definir as classes. 0 critério adotado pela ABEP, pode ser considerado multidimensional, uma vez que utiliza o levantamento de características domiciliares para classificação e diferenciação social em classes econômicas. Na metodologia são atribuídos pontos em função de cada característica domiciliar (número de TVs em cores, rádios, máquinas de lavar, videocassetes/DVDs, geladeiras simples, freezers ou geladeiras duplex, banheiros, automóveis e empregadas mensalistas) e grau de instrução do chefe da família (ABEP, 2012). Posteriormente, é realizada a soma destes pontos e identificados os correspondentes estratos de classificação econômica, que podem ser: A1, A2, B1, B2, C1, C2, D, E.

A representatividade dessa Nova Classe é inegável. De acordo com a Secretaria de Assuntos Estratégicos da Presidência da República (SAE), essa classe representa 54\% da população brasileira sendo a maior do país. A classe média brasileira assumiu expressiva importância no cenário econômico, isto em função do aumento de $228,3 \%$ dos seus gastos com produtos e serviços entre 2001 e 2011 . Assim, neste mesmo período, a classe média ampliou de $25,8 \%$ para $44,3 \%$ a sua participação no consumo nacional, ultrapassando a classe alta, que caiu de $58,5 \%$ para 39,9\% a sua representatividade (BRASIL, 2012).

O Sociólogo Bolívar Lamounier em entrevista à revista Veja em 2010 diz que evidenciando o amadurecimento social e econômico do país, temos a nova classe média se consolidando. 0 aumento dessa classe fez com que a mesma representasse mais da metade da população afirmando ainda mais seu poder de compra. Ainda para o sociólogo, diversos fatores influenciaram a mudança no perfil dessa nova Classe. Maior facilidade a crédito, facilidade de financiamentos, e a possibilidade de comprar um automóvel em sessenta vezes.

Mas, deve-se destacar que a diferença entre essa Nova Classe Média e Classe Média tradicional são muitas. A Classe Média considerada tradicional era composta tipicamente por funcionários públicos, com padrão financeiro estável, devido ao emprego estável. A Nova Classe Média não possui um padrão nítido e homogêneo como a considerada tradicional. Por ser uma classe tão ampla não existe homogeneidade comportamental. Uma forma dessa nova classe se consolidar é através do estudo e de capacitações, não como forma de ostentação como era em outros tempos, mas sim como forma de educação eficiente (LAMOUNIER, 2010).

A ascensão da Nova Classe Média moveu a economia como nunca visto antes. A SAE (Secretaria de Assuntos Estratégicos da Presidência da República) divulgou no final do ano de 2012 que mais da metade da população brasileira fazem parte da classe média e a estimativa, é que se mantidas a taxa de crescimento e a tendência à queda nas desigualdades, a classe média pode chegar a 57\% da população brasileira em 2022(SAE,2012).

As organizações terão de saber lidar com esse novo público e saber quais as aspirações, desejos e motivações da Nova Classe a fim de compreender e atender as exigências desse novo mercado 
tão peculiar.

Meirelles (2011) corrobora quando afirma que a Nova Classe C tem um jeito muito próprio de consumir e ainda acrescenta que as empresas que ignorarem essa Nova Classe não sobreviverão (MEIRELLES, 2011).

Para Douglas e Isherwood (2004), os indivíduos usam o consumo para dizer algo sobre si mesmo. Na busca por uma maior compreensão das motivações, comportamento e influências de consumo da Nova Classe Média, o próximo tópico abordará o capital cultural para dar subsídios para o entendimento de sua influência sobre os padrões de consumo.

\section{Capital cultural}

Pode-se considerar que capital cultural é um processo relacionado à educação, podendo ser formal, no ambiente escolar, bem como social, herdado e influenciado pela família, como gostos preferências e hábitos, portanto, relacionado também a questão social. Bourdieu atribui níveis de capital cultural mais altos às famílias de classes mais altas devido ao acesso facilitado a ambientes culturais específicos, como museus e teatros (BOURDIEU ,1980 mesmo autor distingue o capital cultural de acordo com as classes. Ele acredita que cada classe desenvolve características de acordo com sua trajetória social influenciando também os gostos e preferências, uma vez que "o gosto é o princípio de tudo o que temos, de tudo o que somos para os outros e é através dele que classificamos e somos classificados". (BOURDIEU, 1979. p.59). Ainda, Bourdieu (1979) distingue os gostos em relação às classes e acredita que cada classe tem os tipos principais de gostos: o gosto das classes populares, da classe média e da classe dominante .

Gade (1998) corrobora quando diz que indivíduos de classes semelhantes tendem a apresentar comportamentos semelhantes como valores, atitudes, ocupação com atividades, linguagens e pensamentos. Solomon (2011) destaca a importância em se considerar o lugar que a pessoa ocupa na estrutura social, uma vez que ele determina quanto dinheiro é gasto e como.

Ainda segundo as influências nos gostos e preferências, Bourdieu defende que isso resulta de toda herança cultural do indivíduo, os níveis de capital cultural obtidos pelos meios, como família e escola; tudo isso define as atitudes em relação à cultura (BOURDIEU, 1996). Nesse sentido pode-se notar uma relação direta do capital cultural ao habitus, como forma de unificar e separar pessoas, como estruturador e estruturante. Por meio do habitus podemos classificar gostos e pessoas, escolha de alimentos, bebidas, vestimenta que, dependendo do contexto, pode ser considerado de bom gosto ou não (BOURDIEU, 1996).

O Capital Cultural torna-se, então, um meio de distinção à medida que quem tem maior capital cultural poderá conseguir legitimar sua cultura como melhor (BORDIEU, 1979).

Outro pesquisador que exerceu e exerce grande influência em estudos relacionados ao capital cultural é Holt, que em 1998, estudou o consumo como forma de adquirir status através de uma pesquisa realizada nos Estados Unidos.

Anos mais tarde, em 2010, realizou uma pesquisa na Turquia, onde estudou a relação que as mulheres da nova classe média têm com o consumo de status e produtos culturais (HOLT 1998, 2010). 0 presente estudo tomará o critério utilizado por Holt como base para realizar a mensuração do capital cultural dos entrevistados, conforme será detalhado posteriormente. Holt $(1998,2010)$ acredita que na área da administração a abordagem do critério de capital cultural para estudos de consumo e de bens culturais seja consistente não havendo necessidade de se considerar outros tipos de capitais em conjunto. 
Capital econômico diz respeito a recursos financeiros. Capital social a relacionamentos, filiações.

O capital cultural, por abranger questões profundas como habilidades práticas, gostos raros, conhecimentos adquiridos através do seio familiar dentre outras coisas, foi apresentado de três formas: incorporado, objetivado e institucionalizado. 0 primeiro diz respeito a um capital cultural considerado inato, como uma herança familiar, sendo construído no seio da família e acontece de forma quase biológica, pois acompanha a evolução do indivíduo, o crescimento no ambiente familiar. Esse primeiro tipo de capital influenciará também no futuro escolar do indivíduo, uma vez que tem relação com os ensinamentos passados, o acesso a gostos, culturas e conhecimentos diferenciados e vivenciados, tornando-se um patrimônio familiar que não se adquiri rapidamente, mas é aprendido no dia a dia, tornando-se inato.

O segundo, o capital cultural, denominado objetivado, diferentemente do primeiro, tem a ver com o consumo, com adquirir conhecimento por meio do acesso a compras de bens, como livros, obras de arte, acesso a museus, cinema, etc. No entanto, apropriar-se disso tudo tem relação direta com o primeiro capital, o incorporado, uma vez que para se apropriar simbolicamente é necessário ter um conhecimento, um interesse prévio, adquirido por meio do tipo incorporado de capital. Possui ligação direta também com o capital econômico, uma vez que é necessário ter recursos financeiros para se ter acesso ao capital objetivado. Nesse sentido, torna-se gritante as desigualdades, no sentido de que quem possui condição financeira desfavorecida está sujeito à exclusão desse tipo de capital. Por fim, o capital cultural institucionalizado, é aquele adquirido por meio de títulos e diplomas, possuindo também relação com capital econômico, que facilitará o acesso a esse ultimo tipo de capital cultural (BOURDIEU, 2011; HOLT, 1998).

Bourdieu possui ainda diversos estudos que relacionam o capital cultural ao nível cultural da família e à escolaridade. 0 autor avalia, por exemplo, a influência do nível de escolaridade dos pais em relação ao capital cultural. E destaca ainda que crianças de origem social privilegiada devem ao meio social os hábitos, gostos, familiaridades com itens relacionados à cultura, como teatro, música, cinema, museu, literatura (BORDIEU, 1999). Com isso, nota-se a distinção, no qual cada criança será desigual de acordo com o capital cultural herdado. "Em todos os domínios da cultura, teatro, música, pintura, jazz e cinema, os conhecimentos dos estudantes são tão mais ricos e extensos quanto mais elevada é a sua origem social” (BOURDIEU,2007, p. 45).

Vários estudos realizados no mundo corroboram os pensamentos de Bourdieu. Lata (2013) realizou um estudo objetivando explicar a relação entre o capital cultural e a escolha pelo tipo de universidade feito pelos estudantes- A pesquisa foi realizada em duas universidades de Bangladesh- e mostrou que - pais com nível maior de capital cultural desempenham papel mais importante no processo de tomada de decisão dos alunos.

Outro estudo realizado, esse embasado nas três dimensões do capital cultural de Bourdieu (institucionalizado, objetivado e incorporado) foi o realizado por Eslami, Sahrapeyma e Abotalebi (2013), que procuraram estudar a relação entre o capital cultural dos pais e o rendimento dos alunos de ensino médio. Podemos encontrar estudo semelhante no Brasil, como o de Bonamino, Alves e Franco (2010), que estudaram os efeitos das diferentes formas de capital no desempenho escolar. Oliveira e Melo-Silva (2010) estudaram a influência das variáveis socioeconômicas e culturais na carreira de estudantes universitários de uma instituição publica. Concluíram que a escolaridade dos pais, nível socioeconômico e natureza do ensino cursado estão proporcionalmente relacionados ao sucesso no vestibular e à escolha da carreira. No estudo de Bihari (2013), foi aferido o que há por trás do sucesso escolar de crianças de duas diferentes escolas . Com o estudo, concluiu que o nível de instrução das crianças está condicionado ao interesse, atividade e ao capital cultural e alegou que aqueles que têm mais acesso e poder aquisitivo maior têm, segundo as palavras do autor, "potential to get space in the existing power structure" (BIHARI, 2013, p 33). 
Dunt, Hage e Kelaher (2010) - estudaram o impacto do capital cultural e social dos pais sobre os cuidados com a saúde das crianças australianas.

Schori, Hofmann e Abel (2013) buscaram averiguar as relações entre tabagismo, capital cultural e cuidados com a saúde.

Diante do que foi exposto, nota-se a influência do Capital Cultural sob diversos aspectos na vida do individuo. Além de influenciar gostos, hábitos e escolhas, influencia também no acesso a cultura e ensino, que geram consequências por toda a vida. É possível o individuo modificar sua realidade e alterar ou moldar suas escolhas e hábitos, mas de forma gradativa. Por meio dos estudos citados acima, percebe-se a dificuldade que um individuo de classe desfavorecida tem para driblar o baixo Capital Cultural.

\section{Procedimentos Metodológicos}

Para atingir o objetivo proposto a abordagem adotada foi a qualitativa. Para Minayo (2001) a pesquisa qualitativa não pode ser reduzida a operacionalização de variáveis, uma vez que explora uma gama de valores, atitudes e crenças, que envolve um espaço mais profundo das relações e um universo de significados. Portanto a pesquisa qualitativa mostra-se adequada para o estudo a ser realizado uma vez que visa alcançar uma melhor compreensão do tema pesquisado. Para Bauer e Gaskell (2007), a pesquisa qualitativa é indicada quando há uma preocupação maior com entendimento de um tema, não objetivando assim a generalização. Vale ressaltar que o presente trabalho visa explorar um universo especifico, a cidade de Lavras, não podendo extrapolar assim os resultados para toda a Nova Classe Média brasileira.

Com o objetivo de compreender melhor o tema pesquisado o tipo de pesquisa que se mostrou mais adequado foi do tipo exploratória. Conforme Malhotra (2006) justifica-se esta decisão em função da necessidade de explorar o tema da pesquisa, adquirindo maior conhecimento sobre o mesmo.

Foram realizadas entrevistas em profundidade, utilizando-se de um roteiro semi-estruturado desenvolvido e embasado de acordo com a fundamentação teórica, no intuito de organizar as questões sobre o tema.

A população entrevistada foi composta por 12 homens e por 13 mulheres da Nova Classe Média lavrense. A escolha da cidade de Lavras justifica-se por motivo de conveniência.

O critério utilizado para definição da Classe Média adotado foi o desenvolvido pesa Comissão da Secretaria de Assuntos Estratégicos (SAE), que definiu a Classe Média brasileira como as pessoas com renda familiar per capita entre cerca de $\mathrm{R} \$ 291$ e $\mathrm{R} \$ 1.019$. Tal critério foi adotado devido à relevância que possui para o país como um todo. Foi estabelecido por um órgão do governo por meio de inúmeros estudos. Tais estudos e definições foram criados os cadernos "Vozes da Classe Média", que já está em sua quarta edição, e apresenta todos os estudos realizados pelo governo sobre a Nova Classe Média.

Para delimitar número de entrevistas realizadas utilizou-se o critério de saturação defendido por Minayo (1992), por meio do qual o pesquisador realiza um certo número de entrevistas até haver reincidência nas respostas e nas informações obtidas, não acrescentando assim mais conteúdo as entrevistas permitindo então um abrangência suficiente sobre o assunto abordado. Portanto, com a realização de 25 entrevistas, o critério de saturação foi atingido. Os primeiros entrevistados foram selecionados por conveniência. Os seguintes foram escolhidos pelo método bola de neve, no qual um entrevistado indica outro.

As entrevistas foram transcritas e analisadas utilizando-se a analise de conteúdo de 
Bardin(1979) como técnica.

Para a referida autora, a análise de conteúdo é definida como "um conjunto de técnicas de análise das comunicações, que se utiliza procedimentos sistemáticos e objetivos de descrição do conteúdo das mensagens" (BARDIN, 1979, p. 38).

$\mathrm{Na}$ parte inicial da entrevista foi feita uma caracterização para identificar o perfil do entrevistado e confirmar se o mesmo atendia aos critérios para participação da entrevista. Ainda nessa primeira parte, foram feitos questionamentos para definição do nível de Capital Cultural de acordo com o estudo de Holt (1998; 2007). Neste sentido, foram avaliados a educação do pai (nível de escolaridade) e ocupação do pai, educação e ocupação do entrevistado atribuindo escores aos níveis. Além disso, foram realizadas nesse estudo algumas adaptações a fim de atender melhor aos objetivos da pesquisa e abarcar de forma mais profunda a realidade da amostra pesquisada. A primeira adaptação foi acrescentar a mãe na pesquisa referente ao Capital Cultural, uma vez que a mulher possui cada vez mais participação tanto no mercado de trabalho, como no sustento do lar e educação dos filhos, podendo ser considerada, assim, de grande influência no que diz respeito ao Capital Cultural. Outra adaptação foi em relação aos escores no intuito também de adaptar a realidade estudada. No escore referente à escolaridade onde se tem "curso técnico (3)", foi acrescentado "cursando superior", visto que era a realidade de vários entrevistados e poderia enviesar a pesquisa se os mesmos fossem considerados somente como o escore anterior "ensino médio completo (2)". Utilizou-se então: "curso técnico ou cursando superior (3)", com isso, foi possível definir os níveis de Capital Cultural: baixo capital cultural (BCC) e alto capital cultural (ACC). A Figura 1 apresenta como ficaram os escores referente a escolaridade e a Figura 2 apresenta a classificação da ocupação.

\begin{tabular}{ll}
\hline ESCOLARIDADE & Pontos \\
\hline Menor que ensino médio & 1 \\
Ensino médio completo & 2 \\
Curso técnico/ cursando superior & 3 \\
Curso superior & 4 \\
Pós-graduação/ mestrado & 5 \\
Doutorado & 6 \\
\hline
\end{tabular}

Figura1. Escores referentes à escolaridade

\begin{tabular}{lc}
\hline OCUPAÇÃo & Pontos \\
\hline Serviço manual & 1 \\
\hline $\begin{array}{l}\text { Serviço de apoio/administrativo básico } \\
\text { Vendas, técnico básico, gerencial básico, pequeno empresário }\end{array}$ & 2 \\
$\begin{array}{l}\text { Alto nível técnico ou gerencial, cultural de nível básico (professores ensino primário e } \\
\text { secundário) }\end{array}$ & 4 \\
Produtores culturais, profissional liberal especializado (médico, advogado...) & 5 \\
\hline
\end{tabular}

Figura 2. Escores referentes à ocupa

Para medir o Capital Cultural foi utilizada a seguinte fórmula: ocupação do pai (OP) somada a 
escolaridade do pai (EP) divido por dois, mais a ocupação da mãe (OM) somada a escolaridade da mãe (EM) dividido por dois, mais a ocupação do entrevistado (OE) somada a escolaridade do entrevistado (EE).Temos então: $(\mathrm{OP}+\mathrm{EP} / 2)+(\mathrm{OM}+\mathrm{EM} / 2)+\mathrm{OE}+\mathrm{EE}=\mathrm{CC}$. O Capital Cultural, de acordo com a fórmula pode ter como escore mínimo o valor de 4 e como escore máximo o valor de 22, definindo-se assim os entrevistados como BCC e ACC.

A seguir serão apresentados os resultados.

\section{Resultados}

\section{Caracterização e perfil de consumo dos entrevistados}

Analisando o perfil dos entrevistados observa-se, conforme apresentado na Figura 3 foram vinte e cinco entrevistados no total sendo treze deles são mulheres e doze são homens. Na Figura 3 foi separado por gênero para facilitar a visualização e caracterização dos entrevistados. A maior parte é casada, sete homens e seis mulheres. Cinco homens são solteiros e quatro mulheres também. Somente três mulheres são divorciadas enquanto nenhum homem o é.

Foi definida a colocação de bens e posses na Figura 3 devido à representatividade que esse tópico demonstrou no momento das analises dos resultados. A grande maioria mora em casa própria, sendo dez mulheres e nove homens. Somente três mulheres e três homens moram de aluguel. Oito mulheres e sete homens têm carro próprio e seis mulheres e cinco homens tem moto.

Em relação ao nível de escolaridade é notório que os entrevistados possuem maior nível escolar que seus pais. Enquanto a escolaridade dos pais mais apresentada foi menor que ensino médio isso apresentou de forma única em relação aos entrevistados, ou seja, somente uma mulher e um homem possui escolaridade menor que ensino médio.

O total de entrevistados quanto ao nível de Capital Cultural foi de dez entrevistados com Baixo nível de Capital Cultural (BCC), nove entrevistados com nível Médio de Capital Cultural (MCC) e seis com Alto nível de Capital Cultural (ACC).

Vinte e quatro entrevistados acreditam que o padrão de consumo deles melhorou nos últimos anos. Somente uma entrevistada acredita que manteve o mesmo padrão. Aqueles que afirmaram haver a melhoria a atribuíram aos seguintes fatores: acesso a cartão de crédito e maior acessibilidade a variadas formas de credito, como financiamentos, parcelamentos das compras; melhoria de cargo e, consequentemente, dos salários. Muitos atribuíram a melhoria de cargo ao acesso à educação e maior qualificação do que os pais cuja maioria possui baixa escolaridade.

Os itens mais citados pelos entrevistados como mais acessíveis à compra atualmente foram eletrodomésticos, eletrônicos, carro e moto. Isso aconteceu devido à facilidade de pagamento. È interessante destacar que alguns entrevistados responderam essa questão de forma deslumbrada, alegando que jamais imaginaram ter acesso a esse tipo de itens. Os bens comprados nos últimos anos que eles julgaram mais importantes foram: carro, moto, computador, TV, casa, móveis, celular e eletrodomésticos, nessa ordem.Quando questionados em relação à definição do que seria supérfluo e o que seria necessário, apesar de haver respostas distintas em relação ao que seria supérfluo, todas as vinte e cinco respostas foram relacionadas ao desperdício, ou seja, supérfluo como sendo compras desnecessárias, compras extras, de itens que serão desperdiçados. Já o necessário foi relacionado, primeiramente, aos itens básicos para viver, seguido daqueles que envolvem conforto e lazer. 
Destaca-se o fato de cinco mulheres e um homem enfatizarem a questão da quantidade, alegando que tudo o que consumimos é necessário, o que distingue entre necessário e supérfluo é a quantidade, ou seja, se comprarmos a mais, torna-se supérfluo.

Em relação aos hobbies preferidos dos respondentes, destaca-se a prática de esportes, academia ou caminhada, seguida pelas viagens, assistir TV e navegar na internet. Mesmo com hobbies diferentes, a frequência realizada foi dita como intensa por todos, ou seja, todos têm acesso a seus hobbies preferidos. Corroborando os resultados obtidos, no estudo de Santana et al (2012), a televisão e a internet apareceram em destaque como forma entretenimento, além do acesso frequente às lan houses. De forma diferente deste estudo, todos os entrevistados possuem computador ou notebook com acesso a internet.

Nove do total dos entrevistados já viajaram de avião, todos a passeio, sendo que dois desses também viajaram a trabalho. Dez não viajaram e não têm essa pretensão, pois têm medo e seis não viajaram, mas têm vontade e pretendem viajar algum dia.

Quando questionados sobre a realização de compras em família todos os entrevistados relacionaram a pergunta à compra de supermercado, a compra do mês. Nove responderam não realizar compras em família, sendo que sete são entrevistados solteiros que moram com os pais, cabendo essa função aos últimos. Uma mulher realiza as compras só, por morar sozinha e um homem casado realiza as compras sozinho também. Os outros 16 realizam as compras de supermercado em família e três deles além de compras de supermercado, realizam compras de roupas, utensílios e moveis.

Os itens adquiridos nos últimos anos que tornaram a vida dos entrevistados mais prática foram: moto, carro, notebook ou computador, seguido por máquina de lavar e microondas. Tais itens foram, para a grande maioria, citados como boa relação custo-benefício e - relacionados a melhoria de vida. No que tange esse último aspecto, todos os entrevistados alegaram que a compra dos produtos tornou a vida mais pratica, facilitando atividades do dia-a-dia, agilizando e otimizando o tempo.

Dezessete dos entrevistados fazem controle de gastos, doze entrevistados afirmaram poupar dinheiro. Desses, quatorze planejam as compras, sendo que nove planejam tudo e cinco planejam somente as compras mais caras, como de móveis e eletrodomésticos. Três entrevistados afirmaram não fazer controle algum, não planejar compras, não terem controle dos gastos e, com isso, não terem noção do destino especifico do dinheiro.

Doze entrevistados poupam dinheiro de forma consciente, ou seja, reservam uma parte especifica dos ganhos. Seis desses poupam uma parte do dinheiro por precaução, para alguma eventualidade, os outros seis poupam com objetivos específicos como casamento, viagem, ou investimentos como a compra da casa e poupança. A outra parte dos entrevistados dividiu-se em os que não poupam dinheiro mesmo, os que tentam poupar, ou seja, se sobra algum dinheiro, guardam, mas sem uma finalidade especifica e os que poupam pouco mas queriam poupar mais.

Quando questionados sobre coisas "não materiais" que investem o dinheiro os itens mais citados foram relacionados a cuidados com a beleza: salão, manicure, pedicure, depilação e tratamento capilar, seguido de investimentos em cursos, capacitações para os filhos, pósgraduação e graduação. Investimentos em esportes e academia também foram muito citados seguido por investimento em internet, saúde, viagens e poupança. Sete entrevistados não investem dinheiro em cursos ou capacitações, os outros dezoito investem em capacitações para si ou para alguns familiares, sendo que os familiares citados foram os filhos ou esposas. 
Cinco dos vinte e cinco entrevistados afirmaram não comprar por impulso, sendo que dois disseram não comprar mais por impulso, pois já tiveram problemas financeiros devido à impulsividade na compra. Os outros vinte afirmaram comprar por impulso, sendo os itens mais citados: roupas, sapatos ou tênis, comidas e bebidas.

Nove pessoas citaram roupa como item que dá prazer em comprar, sendo que para três dessas pessoas, o prazer está em comprar roupas para os filhos. Nove pessoas citaram compras relacionadas à alimentação. Nas palavras dos entrevistados: "besteiras, doces, delícias". Sapato também foi outro item citado seguido por cerveja e eletrônicos.

Quando questionados sobre o tipo de compra que faz sentir bem apesar da pergunta ser semelhante à pergunta: Que tipo de compra te dá prazer? A resposta que emergiu com mais intensidade foi representativa. Grande parte dos entrevistados respondeu que comprar faz bem, seja o que for, o ato de comprar, comprar o que se gosta, o que precisa, faz bem. Os outros itens citados foram semelhantes à questão que remete ao prazer: roupa, alimentação e sapato.

Sete entrevistados responderam que a compra de roupa o fazem sentir mais importante, influencia a autoestima fazendo-a sentir-se melhor com ela mesma. Os outros se dividiram entre casa, carro e moto, bens mais caros e duráveis relacionados ao esforço e satisfação de compra. 0 que foi comprado recentemente que fez os entrevistados sentirem-se melhor foi roupa, eletrônicos, carro e moto, respectivamente. Os serviços que o fazem sentir mais relaxados são os relacionados a cuidados com a beleza: arrumar cabelo, manicure, pedicure, atividades estéticas em geral, seguidos de cuidados com o corpo como clube, pratica esportiva ou academia seguido por serviço de internet.

Todos os entrevistados acreditam que as pessoas compram coisas para impressionar e compram muitas vezes sem terem condições financeiras para isso. Os itens mais citados como utilizados para impressionar foram: roupa, carro e celular, respectivamente.

Treze pessoas afirmaram não ouvir e não pedir a opinião dos outros quando vão comprar algo. Para eles, quando estão determinados a comprar, compram independente da opinião de terceiros. Doze entrevistados afirmaram que a opinião de terceiros conta, especialmente sendo alguém mais próximo, como pai, mãe, esposa e amigos. Pedem opinião principalmente para obterem informações relacionadas à durabilidade, qualidade e confiança do produto.

Os entrevistados relacionaram de forma bem contundente produtos de marca à atributos como qualidade, preço, nome/história no mercado e status, respectivamente. Todos mostraram preferencia por produtos de marca relacionados a bens duráveis como eletrodomésticos, eletroeletrônicos, carro, moto. Para eles, os bens considerados "mais caros" devem ser de procedência, pois devem ter uma durabilidade maior. Todos possuem produtos de marca, sendo os principais, eletrodomésticos e eletroeletrônicos. Mas os produtos de marca comprados recentemente foram: tênis, celular e eletrodomésticos, nessa ordem.

Quando questionados em relação ao sonho de consumo, os principais itens foram: carro, casa e viagem sem preocupação com gasto algum. Cinco pessoas que possuem casa própria falaram que o sonho de consumo é a casa dos sonhos, seja no campo, roça, ou uma casa "gigante".

A Figura 3 sintetiza a caracterização dos entrevistados:

CARACTERIZAÇÃO DOS ENTREVISTADOS

\begin{tabular}{lll}
\hline FAIXA ETÁRIA & HOMEM & MULHER \\
$20-29$ & 7 & 6 \\
\hline
\end{tabular}




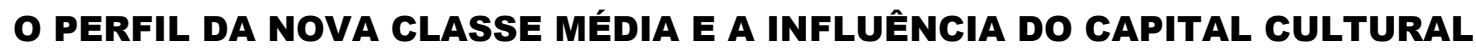

\begin{tabular}{|c|c|c|}
\hline $30-39$ & 5 & 3 \\
\hline $40-49$ & & 3 \\
\hline $50-59$ & & 1 \\
\hline TOTAL & 12 & 13 \\
\hline ESTADO CIVIL & HOMEM & MULHER \\
\hline Casado & 7 & 6 \\
\hline Solteiro & 5 & 4 \\
\hline Divorciado & & 3 \\
\hline BENS E POSSES & HOMEM & MULHER \\
\hline Carro próprio & 7 & 8 \\
\hline Moto própria & 6 & 5 \\
\hline Casa própria & 9 & 10 \\
\hline Mora de aluguel & 3 & 3 \\
\hline Familia (pais e filhos) & 7 & 7 \\
\hline ESCOLARIDADE & HOMEM & MULHER \\
\hline Menor que ensino médio & 1 & 1 \\
\hline Médio completo & 1 & 4 \\
\hline Sup incompleto/ Curso Técnico & 3 & 3 \\
\hline Superior Completo & 4 & 2 \\
\hline Especialização/pós/mestrado & 3 & 3 \\
\hline \multicolumn{3}{|l|}{ Doutorado } \\
\hline ESCOLARIDADE & PAI & MÃE \\
\hline Menor que ensino médio & 11 & 12 \\
\hline Médio completo & 8 & 2 \\
\hline Sup incompleto/ Curso Técnico & 3 & 4 \\
\hline Superior Completo & 2 & 5 \\
\hline Especialização/pós/mestrado & 1 & 2 \\
\hline \multicolumn{3}{|l|}{ Doutorado } \\
\hline BCC & MCC & ACC \\
\hline 10 & 9 & 6 \\
\hline MORADIA & HOMEM & MULHER \\
\hline Sozinho & 1 & 1 \\
\hline
\end{tabular}




\begin{tabular}{lll}
\hline Pais/parente & 4 & 5 \\
Família (pais e filhos) & 7 & 7 \\
FILHOS & HOMEM & MULHER \\
Tem filhos & 3 & 7 \\
Não tem filhos & 9 & 6 \\
\hline
\end{tabular}

Figura 3- Caracterização dos entrevistados

Após essa caracterização do perfil dos entrevistados, torna-se possível um melhor entendimento da influência que o Capital Cultural exerce nos padrões de consumo da Nova Classe Média, conforme será abordado a seguir.

\section{A influência do Capital Cultural}

O nível de Capital Cultural mostrou-se grande influenciador nos hábitos de consumo da Nova Classe Média. Ou seja, pessoas com baixo capital cultural (BCC), médio capital cultural (MCC) e alto capital cultural (ACC) apresentaram padrões de comportamentos distintos.

Os respondentes com BCC privilegiam a compra em si, enquanto os com ACC valorizam momentos proporcionados pela compra de algum produto, os ACC demonstraram nesse sentido uma sensibilidade maior às experiências de consumo. Os tipos de serviços definidos como "serviços que relaxam" também diferenciou-se notoriamente de acordo com o CC, assim como os tipos de viagens realizadas.

Os respondentes da Nova Classe Média com nível alto e médio de CC são mais abertos à opinião de terceiros, escutam e consideram mais a opinião das pessoas, enquanto os respondentes com BCC mostraram-se fechados a receber opiniões. Com relação aos sonhos de consumo as pessoas com BCC demonstraram um conformismo em relação ao que possuem, demonstraram estarem satisfeitas e sem grandes ambições de consumo, enquanto as de ACC almejam novos itens, melhores e mais caros do que os que já possuem.

A Nova Classe Média, de maneira geral, mostrou maior acessibilidade a bens utilitários como eletrodomésticos, eletrônicos, moto e carro, e relacionaram à facilidade de acesso a credito. Relacionaram também às melhorias no dia a dia aos mesmos produtos e alegaram razões semelhantes a essas melhorias, como praticidade e otimização do tempo. As prioridades e motivações de compra também se mostraram as mesmas, independente do nível de CC, ou seja, a Nova Classe Média lavrense compra principalmente por necessidade, valoriza preço e qualidade.

Os entrantes na Nova Classe Média lavrense demonstram maior insegurança em relação ao futuro, por isso poupam com o principal objetivo de ter condições financeiras favoráveis no futuro. Esse resultado mostrou-se ainda mais evidente nas respostas dos entrevistados que têm filhos, esses demonstram uma preocupação ainda maior em relação ao futuro da família.

Nota-se também o valor que essa classe confere aos estudos, aos quais são atribuídas as melhorias nas condições de vida. Essa constatação ficou muito clara logo na caracterização dos entrevistados, onde foi possível notar que todos os entrevistados possuem maior nível de escolaridade que seus pais, no caso dos classificados com ACC mantiveram o nível de escolaridade. Com isso comprova se o que Meirelles (2011) afirmou em pesquisas voltadas para a classe média, onde afirma que essa nova classe busca melhor colocação no mercado através do 
estudo.

De maneira geral, foi possível observar como a influencia do Capital Cultural é representativa. Corroborando assim o pensamento de Bourdieu $(1983,1979)$, que aborda a influencia direta do CC nos gostos, hábitos, preferencias. Bourdieu (1996) defende que a herança cultural do individuo é obtida através da família e escola. Nesse sentido o presente estudo corrobora isso uma vez que os entrevistados que apresentaram ACC apresentam níveis de escolaridade similares aos dos pais. No entanto, grande parte dos entrevistados foi denominado como BCC ou MCC de acordo com a escala utilizada adaptada da escalda de Holt devido à escolaridade dos pais. Conforme exposto no decorrer das analises ficou claro que todos os entrevistados possuem nível de escolaridade mais altos do que o dos pais, mostrando assim um interesse agudo da Nova Classe Média pela qualificação e melhor colocação no mercado. Ficou claro também que para muitos entrevistados o padrão de consumo melhorou devido às melhorias proporcionadas pela politica e pela facilidade de acesso ao credito e, no caso de alguns, devido a melhores empregos, voltando assim à ênfase mais uma vez as capacitações.

\section{Considerações Finais}

Com as análises das entrevistas foi possível identificar os padrões de consumo da Nova Classe Média e como o Capital Cultural influencia tais padrões. Nesse sentido foi possível relacionar os resultados com pesquisas já feitas e apresentadas nesse estudo.

Pode se notar como o CC cultural influencia em diversos aspectos os hábitos e padrões de consumo. Nota se que parte da Nova Classe Media lavrense é composta por novos entrantes, ou seja, pessoas que emergiram de classe mais baixas e hoje encontram se na classificação de Nova Classe Média, assim como por pessoas que já se enquadravam nessa classificação. Essa heterogeneidade traz implicações em vários aspectos, como observado através das entrevistas.

Os novos entrantes são as pessoas com BCC e MCC. Tornaram-se novos entrantes devido a melhorias salariais ocasionadas pela qualificação, como o maior nível de escolaridade, se comparadas aos seus pais, o que proporcionou a esses indivíduos melhor colocação no mercado, consequentemente melhores salários, impulsionando uma serie de melhorias e mudanças, como maior acesso a bens, possibilidade de comprar casa, carro, de oferecer capacitações para os filhos. Talvez nesse último ponto encontra-se a chave para a sustentabilidade dessa Nova Classe. Os entrantes consideram o estudo como um diferencial e proporcionador dessas melhorias e dessa nova colocação de classe e veem isso para o futuro dos filhos também. Com a constante capacitação tornar-se-á mais fácil o futuro dos nascentes nessa Nova Classe Média, ou seja, os filhos da Nova Classe Média. No entanto esses novos entrantes trazem consigo resquícios do passado como o medo e insegurança em relação ao futuro, conforme claramente exposto nas entrevistas. Os respondentes mostraram-se satisfeitos e felizes com a atual situação, mas temem o futuro à medida que todos poupam ou pelo menos tentam poupar como medida de precaução.

Aqueles que já pertenciam a Classe Média e continuam nessa classificação possuem em geral o mesmo nível de escolaridade que os pais e mantiveram o mesmo padrão de vida que tiveram durante a vida.

Para os crescidos na Classe Média, o padrão de vida melhorou no que diz respeito à acessibilidade ao credito, assim como alegaram os novos entrantes, no entanto, esses indivíduos relacionaram às melhorias as novas ofertas de mercado e a economia em geral.

Os entrevistados que se mantiveram na Classe Média são os classificados como ACC de acordo com a escala utilizada. Para esse grupo, estudar, conseguir comprar casa e carro aconteceu de maneira mais natural do que para os novos entrantes. Provavelmente, pelo fato de terem 
capacitado e buscado ensino superior de forma natural. 0 ensino continuado fez e faz parte da criação dos mesmos.

Nesse sentido, a influência do Capital Cultural, conforme defendido por Bourdieu (1986), é corroborada. Os já pertencentes à Classe Média, continuaram nesse patamar devido à criação e aos estudos proporcionados pela família, nesse sentido, tendo acesso aos três tipos de Capital Cultural defendido por Bourdieu. No entanto, os indivíduos considerados novos entrantes contrariando os estudos de Bourdieu conseguiram traçar uma historia diferente e demonstram interesse em fazer essa mudança perdurar.

Algumas constatações podem gerar implicações gerenciais consideráveis, como o fato dessa nova classe demonstrar grande sensibilidade a apelos visuais e promocionais. Valorizar momentos de lazer e principalmente serviços de beleza e estética, definidos pelos próprios entrevistados como serviços que relaxam. Nesse sentido todos fazem investimentos em si, sentem prazer e pagam sem relutar num sentido de autogratificação. 0 fato de privilegiarem também o conforto do lar mostrando preferencias por serviços delivery também traz implicações gerenciais importantes. Os gestores que atentarem-se para essas observações poderão adaptar e melhorar os serviços prestados e produtos ofertados a fim de atender melhor esses consumidores. Assim, poderão atingir de forma mais direta e satisfatória esse nicho de mercado que hoje se mostra com significativo poder de compra.

0 presente estudo também colabora teoricamente, uma vez que procurou afinar o critério para classificação do nível de Capital Cultural validado e utilizado por Holt (1998; 2007). Com adaptações para a realidade do estudo. Nesse sentido, foram realizadas duas adaptações, uma acrescentando o tópico "cursando superior" e outra acrescentando a ocupação e nível de escolaridade da mãe no calculo de identificação do nível de Capital Cultural. Isso possibilitou maior aproximação com a realidade da amostra pesquisada uma vez que com a adaptação pôdese abarcar ao nível de CC dos progenitores e não somente do progenitor, como no modelo de Holt. A consideração dos níveis de CC tanto do pai quanto da mãe se mostrou relevante tendo em vista que alguns respondentes foram criados somente pelas mães e, em vários casos, as mães possuíam nível de escolaridade alto, o que fez diferença quando calculado o nível de CC.

A adaptação do critério utilizado por Holt, impulsiona estudos futuros utilizando o critério adaptado da presente pesquisa, possibilitando a validação do mesmo.

Durante toda a pesquisa foi evidenciado o poder de consumo e de decisão de compra dessa Nova Classe, denominada como Nova Classe Média, que pode alterar as formas de consumo. Nesse sentido é interessante estudar mais afundo os desejos e anseios dessa Classe tão representativa. Diante da representatividade da Nova Classe Média sugere-se estudos mais abrangentes, visto que a pesquisa foi realizada em âmbito local. Além de aumentar a abrangência do estudo sugere-se também estudos quantitativos a fim de dimensionar o comportamento desses consumidores e verificar a influencia dos diferentes níveis de Capital Cultural.

Outro ponto que pôde ser observado no desenvolvimento do trabalho foi o fato de ainda se fazer presente a dificuldade na definição das classes sociais. Na década de 70 e 80 as visões eram dicotômicas e respondiam ao cenário econômico da época.

Com a evolução da sociedade vieram as estratificações das classes passando então de divisões dicotômicas para múltiplas, sendo que o critério prevalecente ainda é a renda. Com isso, têm-se ainda uma visão voltada para o econômico, sendo, muitas vezes incompleta. Neste sentido cabe como sugestão a realização de estudos futuros voltados às definições de classes e seus critérios. Verificar se os critérios atuais atendem às necessidades atuais da sociedade para se caracterizar e delimitar cada classe. 


\section{Referências}

ABEP - Associação Brasileira de Empresas de Pesquisa. Critério de Classificação Econômica Brasil. 2012.

BARDIN, L. Análise de conteúdo. Lisboa: Edições 70, 1979.

BARROS, M. B.de A. A utilização do conceito de classe social nos estudos dos perfis epidemiológicos: uma proposta. Rev. Saúde públ., S.Paulo, 20:269-73, 1986

BAUER, M. W.; GASKELL, G. Pesquisa qualitativa com texto, imagem e som: um manual prático. Rio de Janeiro: Vozes, 2007.

BIHARI, S. Cultural Capital and School Success. International Journal of Research in Sociology and Social Anthropology, 1(1), 33-38, 2013.

BONAMINO, A., ALVES, F., FRANCO, C., \& CAZELLI, S. The effects of the different forms of capital on school performance: a study illuminated by Bourdieu and Coleman. Revista Brasileira de Educação, 15(45), 487-499, 2010.

BOURDIEU, P. A economia das trocas simbólicas. São Paulo: Perspectiva, 2007.

BOURDIEU, P. Algumas propriedades dos campos. In: BOURDIEU, P. Questões de sociologia. Rio de Janeiro: Marco Zero, 1983.

BOURDIEU, P. La distinction. Paris: Les Éditions de Minuit, 1979.

BOURDIEU, P. Razões práticas: sobre a teoria da ação. São Paulo: Papirus, 1996.

BRASIL. Presidência da República. Secretaria de Assuntos Estratégicos. Vozes da classe média. Brasília: Marco Zero, 2012.

DOUGLAS, M , ISHERWOOD, B. 0 mundo dos bens - para uma antropologia do consumo. Rio de Janeiro: EdUFRJ, 2006

DUNT, D.,HAGE, B., KELAHER,M.,The impact of social and cultural capital variables on parental rating of child health in Australia. Health Promotion International, Vol. 26 No. 3, nov 2010

ESLAMI, S.,SAHRAPEYMA, M., ABOTALEBI, N. Investigation the relationship between objectified cultural capital of parents with academic achievement of high school students Disponível em: http://www.sciencepub.net/researcher/research0512/012 21308research0512 91 96.pdf.

Acesso em: jan 2014.

ESTANQUE, E. 0 'efeito classe média' - desigualdades e oportunidades no limiar do século XXI. Centro de estudos sociais: Faculdade de Economia da Universidade de Coimbra, 2002. Disponível em: http://www.ces.uc.pt/publicacoes/oficina/ficheiros/172.pdf. Acesso em: jan/2013

GADE, C. Psicologia do consumidor e da propaganda. São Paulo: EPU, 1998.

HOLT, D. Does Cultural Capital Structure American Consumption?. Journal of Consumer Research, v.25, jun. 1998.

HOLT, D. Üstüner, Tuba. Toward a Theory of Status Consumption in Less Industrialized Countries. Journal of consumer research, vol. 37, june, 2010.

IBGE (Instituto Brasileiro de Geografia e Estatística).Pesquisa Nacional por Amostra de 
Domicílios: síntese de indicadores de 2005. Rio de Janeiro: IBGE, 2006.

LAMOUNIER, B.. VEJA.São Paulo, edição 2.160, ano 43,n.15,14 abr.2010

LATA, L. N. . Cultural capital and higher education in bangladesh. International Review of Modern Sociology, 39(2), 2013.

MALHOTRA, N. K. Pesquisa de marketing: uma orientação aplicada. 4. ed. Porto Alegre: Bookman, 2006.

MATOSO, Cecília. Classes Sociais: uma discussão sobre os conceitos na Sociologia e

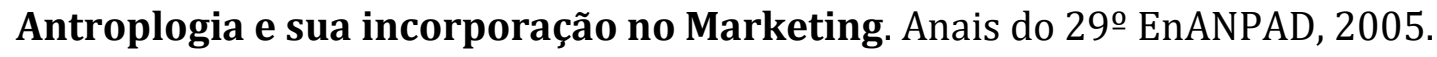

MEIRELLES, Renato. Brasil emergente: dossiê sobre a classe $\mathbf{C}$ brasileira; um mercado de R\$ 881 bilhões - versão preliminar. São Paulo: Data Popular, 2011.

MINAYO, M. C. S. 0 desafio do conhecimento: pesquisa qualitativa em saúde. São Paulo-Rio de Janeiro, HUCITEC-ABRASCO, 1992.

MINAYO, M. C.S. Ciência, técnica e arte: o desafio da pesquisa social. In: MINAYO, Maria. C. S (Org.). Pesquisa social: teoria, método e criatividade. Petrópolis, RJ: Vozes, 2001, p.09-29.

MINAYO, M.C.S. Pesquisa social: teoria, método e criatividade. 26ª edição, Rio de Janeiro: Vozes, 2007.

NERI, M. C. A nova classe média: o lado brilhante dos pobres. Rio de Janeiro: FGV/CPS. 2010.

OLIVEIRA, M.D., MELO-SILVA, L.L. ,Estudantes universitários: a influência das variáveis socioeconômicas e culturais na carreira. Revista Semestral da Associação Brasileira de Psicologia Escolar e Educacional- SP, Volume 14, Número 1, p 23-34, jan/jun 2010.

PARENTE, J.; LIMEIRA, T.M.V.; BARKI, E. (org). Varejo para a baixa renda.Porto Alegre: Bookman, 2008

PRADO, M.,E.. Leituras da colonização portuguesa no Brasil do século XX. Revista Intellectus, p. 1-14, 2008.

PRAHALAD, C.K. A Riqueza na Base da Pirâmide: erradicando a pobreza com o lucro. Ed. Ver. Atual. Porto Alegre: Bookman, 2005

SALATA, A. Notas sobre a tese da nova classe média brasileira. 2012

SCHIFFMAN, L. G.; KANUK, L. L.. Comportamento do Consumidor. 6ª Edição. Rio de Janeiro: Editora LTC, 2000.

SCHORI, D., HOFMANN, K., \& ABEL, T. Social inequality and smoking in young Swiss men: intergenerational tansmission of cultural capital and health orientation. International journal of public health, 1-10, 2013

SINGER,P.I. Dominação e desigualdade: estrutura de classes e repartição da renda no Brasil. Rio de Janeiro, Paz e Terra, 1981

SOBRINHO, G. G. de F. X,. A “Classe C" e sua alardeada ascensão: nova? Classe? Média?. Indicadores Econômicos FEE, v. 38, n. 4, 2011.

SOLOMON, M. (2011), Consumer Behavior: Buying, Having and Being, New Jersey, Pearson Education Inc. 